\title{
Contributions of sociology to forest management and policy development
}

\author{
by John Parkins ${ }^{1}$
}

\section{Introduction}

As a sociologist working with the Socio-economic Research Network at the Canadian Forest Service, I am regularly asked to describe the contributions of forest sociology to modern forest management and policy development. This article addresses this question by defining sociology as an applied discipline and outlining the contributions of sociology to three broad areas of current forest research and policy development: global environmental change, ecosystem management, and management information systems.

\section{Defining and applying sociology to the forest sector}

Sociology studies human behaviour and relationships. It examines the effects of society and group membership (see Fig. 1) upon human behaviour. It also explores individuals' perceptions of their society and groups, and the effect of these perceptions upon their behaviour and social interactions (Teevan 1992). While an understanding of individual and group
Forest Science and Technology Board Professional Paper Forest Economics and Policy Working Group icy analysis, particularly with respect to distributional effects of policy (who wins, who loses). In brief then, some of the major objectives of sociology are to: discover structure in society, identify forces which integrate and disintegrate society, and understand conditions which change society.

Sociology is a tremendously diffuse and diverse discipline, not only in terms of sub-

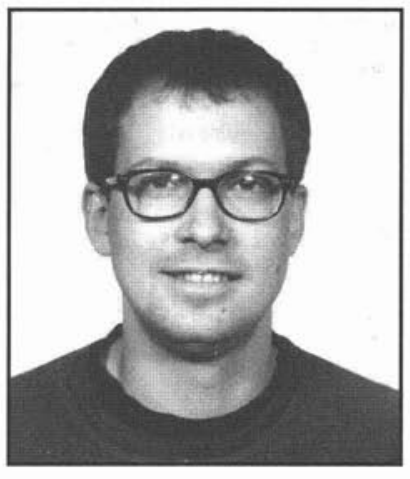
ject matter, but in terms of its practitioners, its theoretical underpinnings, and its methodological approaches. These differences result in a number of dynamic tensions that exist within the discipline. Historically, sociology has struggled to establish itself in the broader science community. A result of this struggle has been an attempt to format research along the

behaviour is key to the discipline, sociologists also attempt to categorize behaviour into larger societal structures. Some of these traditional structures include the relationships between occupation, ethnic origin, and social status. Social structures in the forest sector include the relationship between forest industries and forest-dependent communities, the social impact of absentee ownership versus local ownership, and the specific conditions that define an individual's sense of place in relation to the natural and human environment.

An example of group membership affecting attitudes toward the development of commercial logging comes from a study in Fort Liard, NWT. When asked if commercial logging should continue, $58 \%$ of women said "no," while $74 \%$ of men said "yes." Similarly, differences in attitudes toward commercial logging were recorded between bush users and non-bush users. This research reveals competing interests within a single community and provides input into the likely distribution of benefits from commercial logging development.

Fig. 1. Differential group responses to potential commercial forestry development.

Sociologists contribute significantly to the discussion and critique of policies and policy frameworks that effect specific groups such as Aboriginals, forest sector workers, women, and youth (see Fig. 2 for a larger list). Sociology, therefore, has a role at both ends of policy development. It can provide basic information to help define parameters of key social problems (and who is affected by them), and it can help in pol-

${ }^{1}$ Canadian Forest Service, 5320 - 122 St., Edmonton, AB T6H 3S5. E-mail: jparkins@nrcan.gc.ca lines of the traditional scientific method (e.g., development of quantitative models, rigid hypothesis formulation, modelling, testing, etc.). More qualitative, historical, narrative methods are also popular in the discipline, however. Proponents of this type of work believe that knowledge may be advanced on issues of interest to sociologists through other methods than merely quantitative ones.

While sociology is relatively new to the scientific research agenda in the forest sector, it is beginning to carve out a dis-

- entire societies such as Canada and the United States

- regional groups such as western Canadians or eastern

Newfoundland residents

- trade unions

- environmental groups

- forest industry employees

- Aboriginal communities

- forest-dependent communities

- amenity forest users (hikers, cottage owners, canoeists, birdwatchers)

- social categories: urban Canadians, rural Canadians, men, women, youth, seniors, single adults.

Fig. 2. Groups often included in forest sociology research.

tinctive role in addressing some of the overarching issues in society today. One of these issues is the general concern for sustainable forest management. Toward this end, sociology can provide a unique set of concepts and techniques.

According to Cernea (1994), a leading World Bank sociologist, sociology provides a set of concepts that help explain social action, the relationships among people, their complex 
An example of techniques to prompt coordinated social action and to foster association include projects that evaluate public involvement strategies and recommend ways to enhance public participation. Consensus forest management in northwest Saskatchewan is an example where co-management theory is reviewed and compared to current co-management arrangements on the NorSask FMLA. Research reveals that while the path to true partnership is not easy, partners remain dedicated to active dialogue and a unique solution to meet the needs of northSaskatchewan residents.

Fig. 3. Refinements to public involvement initiatives.

forms of social organization, their institutionalized arrangements, and the culture, motives, stimuli, and values that regulate their behaviour in relation to one another and to natural resources. Also, sociology provides a set of social techniques (Fig. 3) apt to prompt coordinated social action, inhibit detrimental behaviour, foster association, craft alternative social arrangements, and develop social capital.

\section{What is the role of forest sociology in three areas of forest research?}

With regard to the three broad forest sector research themes identified in the first paragraph, sociology can offer some specific research contributions. Arguably the most pressing area of concern is global environmental change. Often abbreviated in policy discussions to global change, it is broadly defined as environmental transformations that threaten the biosphere. Presently, these threats include: climate change, loss of biodiversity, and ozone depletion (Stern et al. 1992). All of these threats have a significant anthropogenic component. In other words, they are in some way a result of human activity, and in that sense they are of prime concern to sociology. Social impact, community impact, and risk assessments are common sociological approaches to addressing these issues, but perhaps more pertinent in global change, and climate change more specifically, is the social construction of environmental knowledge (Buttel and Taylor 1992). The simplified premise behind social constructionism is that no condition is a social problem unless groups with some power consider it one. Therefore, constructionists focus on the claims-making activity of these groups, asking not whether the claim is valid but whether the claims made by these groups are viable - will they hold sway in the public arena? Added to claimsmaking activity is the idea that public attention is a limited commodity, allocated through competition in a public domain. Competition, observed in current public debate, comes from other pressing social problems such as health care, education, welfare, and the economy. Ultimately, recognition of social problems such as climate change, loss of biodiversity, and ozone depletion, through claims-making, depends not only on the viability of the claim itself but on the receptivity of the audience (Fig. 4).

A second area of interest in current forest policy development is ecosystem management. Definitions of ecosystem management are often as varied as contemporary forest management practices but most approaches "focus on similar goals such as restoring and maintaining ecosystem processes and functions, providing goods and services within ecosystem capabilities, and considering humans an integral component of ecosys-
An example of sociological applications to climate change includes determining forest industry perceptions of climate change in light of scientific uncertainty and assessing forest industry willingness to participate in government initiated adaptive and mitigative strategies. While there is strong evidence in support of anthropogenic climate change, many climate scientists remain unconvinced by the evidence, suggesting that industrialized countries can do little to affect climate change. Research addressing this often-overlooked aspect of climate science uncertainty could determine how industry is currently responding to this uncertainty, the willingness of the forest industry to participate in government-led initiatives, and what kinds of information might be most useful in achieving "buyin" from industry on strategic adaptive and mitigative activity.

Fig. 4. Assessing climate change uncertainty in the forest sector.

tems" (Allen 1997). Ecosystem management is the successor to a simple linear cause-and-effect model involving an industrial variable (fibre supply) and a socio-economic variable (community stability). While the sustainable yield approach made a direct connection between a stable timber supply and stable human communities, the ecosystem approach demands a more sophisticated and dynamic analysis of factors contributing to sustainable development that include environmental integrity, social capital, community values, and financial flows. In essence, ecosystem management requires more data - more varied and more detailed. It requires knowledge of flora and fauna but also an understanding of social and economic systems and their links with bio-physical systems (Machlis et al. 1997). Sociologists are capable of enhancing the human dimensions of ecosystem management through a variety of broad research themes. These themes currently include: public involvement, changing forest values, indicators of community sustainability, and subsistence and non-industrial forest use (Fig. 5).

A third area of interest in current forest policy development is knowledge management and information systems. Unlike other policy directions, there is little social theory contributing to its development, but rather a more pragmatic attempt to harness the explosion of scientific information available to resource managers. Here groundbreaking opportunities exist to link biophysical data with socio-economic data and to construct social inventories of forest values and forest uses much like foresters have done for decades with biophysical data (Fig. 6).

\section{Emerging issues and demands}

In terms of emerging research needs, the issue of effective public involvement in public land management is becoming more important. Given Canada's vast tracts of public forests, increasing demands from often conflicting users such as natural resource companies, recreational users, conservationists, and forest-dependent communities, along with prominent Aboriginal claims and management rights, the resolution of forest management conflicts through timely and effective public participation initiatives is going to become increasingly important in the years ahead.

Another area of increasing demand for forest sociology is the issue of community sustainability in the forest sector. According to the 1991 census, there are more than 300 heavily timber-dependent census sub-divisions (CSDs), and more than 1200 
An example of sociological applications to ecosystem management is a CFS project that documented subsistence and non-industrial forest use in the lower Liard Valley, NWT. This study determined the extent to which local residents were using the forest for such activities as hunting, trapping, berries, fuelwood, and craft materials such as birchbark. These uses were then converted to dollar values to show that, on average, $30 \%$ of local household income is derived from non-industrial forest uses. Land managers can use this information in determining ecosystem management plans that incorporate the commercial value of certain non-timber forest activities and the specific geographic locations where such activity takes place within the ecosystem.

Fig. 5. Subsistence and non-industrial forest use.

moderately timber-dependent CSDs in Canada. Each one of these communities is faced with similar challenges as they enter the next century. Labour-saving technology in the natural resource sector, more intensive and multiple uses of the resource base, growing global competition, cyclical commodity prices, a more educated work force, and increasing wealth disparities are affecting social relations in many forest-dependent communities. Community leaders are increasingly concerned with the long term well-being of their communities and are seeking ways to monitor the potential for community sustainability in light of these trends. CFS sociologists are working with these communities to develop appropriate social indicators of community sustainability that focus not only on traditional indicators such as employment and average income levels but indicators that reflect the adaptive qualities required by communities if they are going to survive into the next century. These social indicators often include human capital as reflected by entrepreneurship and education attainment levels, and the extent of community cohesion expressed in the willingness and ability of communities to "pull-together" during times of crisis.

\section{The future of sociology in forest management}

In a recent discussion with an Alberta pulp mill manager, the manager commented that "sustainable forest management is a social question, not a technical one - society chooses what is important to sustain." With an increasing recognition of multiple values and multiple uses on finite forest resources, these social questions will become more and more difficult to answer. Sociologists are working on a range of key issues in the forest sector and while the issues presented above (public involvement and community sustainability) are universal, distinctive regional issues are equally important. From the sustainability of private woodlot management in the Maritimes to labour shedding in resource sectors in Quebec,
A current project sponsored by the Canadian Model Forest Network will develop social indicators of community sustainability such as poverty rates, education levels, and income distributions for model forest locations and link them to GIS maps sheets. In the future, these map sheets may also include other geographic characteristics such as levels of economic diversity, geographic isolation from urban centres, types of forest use such as industrial forestry or subsistence forest activity, and other variables such as the extent of financial leakage from the local economic base. These linked databases and GIS maps can put more accurate and comparable information into the hands of professional foresters and policy makers in more intuitive and user-friendly formats.

Fig. 6. Managing socio-economic inventories.

from competing amenity and commodity uses of forest land in Ontario to the social consequences of industrial restructuring in British Columbia, all point to the growing demand for research in forest sociology.

As a final comment, I should emphasize the expanding range of social groups supported by forest sociology research. Residents of forest-dependent communities, hunters, campers, conservationists, and Aboriginal people are just a few of the groups included in recent research activity. These Canadians are increasingly vocal about their claims on Canada's forested land and, as a result, the issues they raise are becoming more important research activities. By bringing the interests of these divergent and often conflicting groups to the scientific research agenda, sociologists are striving to bring the best information forward in support of forest management and policy development.

\section{References}

Allen, S. 1997. A social scientist's view of ecosystem management. Forest Science, September.

Buttel, F. and P. J. Taylor. 1992. Environmental sociology and global environmental change: A critical assessment. Society and Natural Resources 5: 211-230.

Cernea, M.M. 1994. The sociologist's approach to sustainable development. In I. Serageldin and A. Steer (eds.). Making development sustainable. From Concepts to Action. Environmentally sustainable development occasional paper serves no. 2. Washington: World Bank.

Machlis, G.E., J.E. Force and W.R. Burch Jr. 1997. The human ecosystem. Part I: The Human ecosystem as an organizing concept in ecosystem management. Society and Natural Resources 10:347-367. Stern, P.C., O.R. Young and D. Druckman. 1992. Global environmental change: Understanding the human dimensions. Washington: National Academy Press.

Teevan, J.J. 1992. Introduction to sociology. A Canadian focus (Fourth Edition). Prentice Hall, Scarborough, ON. 